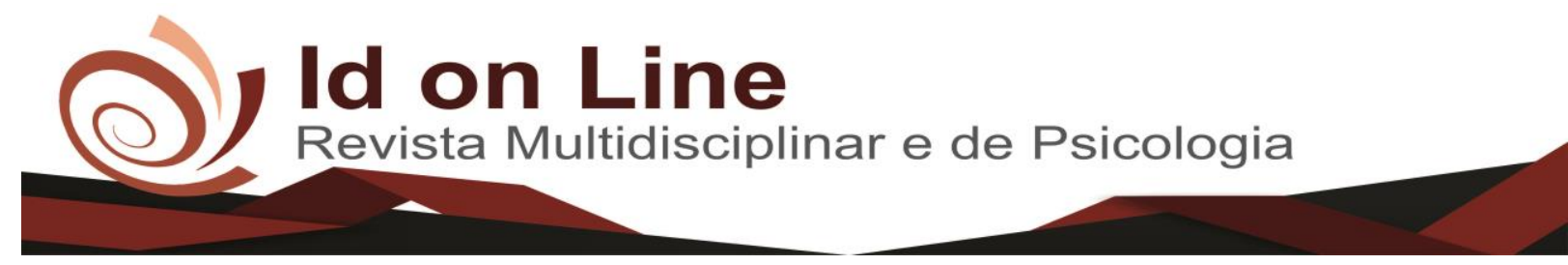

Artigo

\title{
Prevalência dos Acidentes de Motocicleta Envolvendo os Adolescentes de Quixadá
}

\author{
Francisco Hilângelo Vieira Barros ${ }^{1}$, Leonardo Oliveira Silva ${ }^{2}$, Maria Alcione Silva Gomes Roseno ${ }^{3}$, \\ Antônia Gomes de Olinda ${ }^{4}$, Joaquina Batista Rodrigues de Souza ${ }^{5}$, João Joaquim Freitas do Amaral ${ }^{6}$
}

Resumo: O impacto na sociedade e na saúde provocado pelos acidentes de trânsito tem sido extremamente registrado. O objetivo deste estudo retrospectivo e transversal foi conhecer o perfil epidemiológico dos acidentes de motocicletas em adolescentes do município de Quixadá-Ceará. Prevaleceu o sexo masculino (92\%), entre 14 a 17 anos (52\%), no ensino médio (86\%), solteiros $(71 \%)$, com renda familiar entre uma a três salários mínimos (53\%), utilizavam a motocicleta para trabalhar $(61 \%)$ e predominando a profissão mototaxista (43\%). Em relação à motocicleta, $27 \%$ eram habilitados, $2 \%$ referiram conhecer o Código de Trânsito Brasileiro, $13 \%$ faziam uso do capacete, $65 \%$ não praticam direção defensiva, $02 \%$ conhecem a lei $11.705,03 \%$ participaram de programas educativos. O estudo identificou o perfil epidemiológico e os possíveis fatores determinantes dos acidentes envolvendo os adolescentes. Conclui-se que é necessária a intensificação de campanhas educativas sobre acidentes de motocicleta em adolescentes, principalmente nas escolas.

Palavras Chaves: Acidentes de Trânsito. Saúde do Adolescente. Saúde Pública.

\section{Prevalence of Motorcycle Accidents Involving the Adolescents of Quixadá, State of Ceará}

\begin{abstract}
The impact on society and health caused by traffic accidents has been extremely recorded. The objective of this cross-sectional retrospective study was to know the epidemiological profile of motorcycle accidents in adolescents in the city of Quixadá-Ceará. Prevalence of males (92\%), between 14 and 17 years old (52\%), high school (86\%), single parents (71\%), family income between one and three minimum wages (53\%) to work (61\%) and the mototaxista profession predominated (43\%). Regarding the motorcycle, $27 \%$ were qualified, $2 \%$ reported knowing the Brazilian Traffic Code, $13 \%$ used the helmet, $65 \%$ did not practice defensive driving, $02 \%$ knew the law 11,705, 03\% participated in educational programs. The study identified the epidemiological profile and possible determinants of accidents involving adolescents. We conclude that it is necessary to intensify educational campaigns on motorcycle accidents in adolescents, especially in schools.
\end{abstract}

Keywords: Traffic Accidents. Adolescent Health. Public health.

\footnotetext{
${ }^{1}$ Mestrando em Saúde da Criança e Adolescente pela Universidade Estadual do Ceará, Fortaleza-CE, Enfermeiro do Hospital Universitário de Grande Dourados-MS; fhvbqxda@yahoo.com.br

${ }^{2}$ Especialista em Enfermagem - Terapia Intensiva pela Faculdade do Trabalho, Uberlândia-MG, Enfermeiro do Hospital Universitário de Grande Dourados-MS;

${ }^{3}$ Especialista em Unidade de Terapia Intensiva pela Faculdade Integrada de Patos-PB, Enfermeira do Hospital Universitário de Grande Dourados-MS;

${ }^{4}$ Especialista em Enfermagem em UTI Pediátrica e Neo Natal pela Faculdade Unyleya, Brasília-DF, Enfermeira do Hospital Universitário de Grande Dourados-MS;

${ }^{5}$ Docente de enfermagem na Universidade Estadual de Mato Grosso do Sul, Técnica de Enfermagem do Hospital Universitário de Grande Dourados-MS;

${ }^{6}$ Médico, Doutor em Epidemiologia pela Universidade Federal de Pelotas-Fortaleza/Ceará, Docente Adjunto em Pediatria da Faculdade de Medicina da Universidade Federal do Ceará-UFC.
} 


\section{Introdução}

O surgimento dos veículos veio simplesmente favorecer uma melhor interação e locomoção entre as pessoas e grupos. Na proporção que a população vem crescendo, a frota de veículos também aumenta, isso se deve principalmente às facilidades de aquisição dos mesmos. Com isso surgem problemas relacionados ao tráfego, sendo que estas não conseguiram acompanhar tal crescimento.

A frota brasileira em dez anos cresceu 119\% atingindo um total de 64.817 .974 milhões de veículos em dezembro de 2010. Considerando o Censo do IBGE 2010, que indica que a população brasileira é de 190.732 milhões, o país tem uma média de um carro para cada 2,94 habitantes. Sendo o Ceará o terceiro estado nordestino com 1.711.998 milhões (DENATRAN, 2010).

Os elevados índices de acidentes de trânsito andam paralelo ao crescimento da frota de veículos, considerando-se "epidemias" atualmente existentes em todo o mundo, os mesmos vêm se inserindo na agenda da saúde pública com as morbi-mortalidades por causas externas.

Segundo dados do RENAINF, o excesso de velocidade é a infração mais cometida por veículos fora do estado de emplacamento; desde janeiro de 2004, quando o sistema começou a ser implantado no país, até julho de 2010 foram registradas 22.780 .514 infrações de trânsito, dos quais 9.834.097 foram por excesso de velocidade (DENATRAN, 2010).

Várias são as causas relacionadas e classificadas como sendo as principais vilãs no quesito acidentes de trânsito; podendo citar o comportamento das pessoas, assim como a precariedade da engenharia das rodovias e a deficiência nos veículos, sendo esta última melhorada nos últimos anos.

Em se tratando dos jovens, podemos apontar atitudes comportamentais próprios desta faixa etária, tais como: a busca por adrenalina vivenciada ao risco de morte, assim como a procura por novidades e o ser ousado. Tudo isso associado a falta de experiência faz crescer o risco de acidentes.

Os Acidentes de trânsito representam importante carga social, não apenas pelos óbitos e sequelas que causam, mas também por onerar a sociedade com custos diretos e indiretos, valor anual estimado em 1 a $2 \%$ do PIB (JOMAR et al, 2011). 
O impacto na sociedade e na saúde provocado pelos acidentes de trânsito tem sido extremamente registrado, pois o risco de traumas e consequentemente internação das vítimas constituem um indicador da gravidade da gravidade dos acidentes, em especial os acidentes co os usuários de motocicleta (ANDRADE et al, 2009).

A motocicleta se destaca dentre os principais transportes envolvidos nesses dados, uma vez que seu uso vem crescendo em proporções alarmantes e consequentemente os seus problemas tornaram-se mundial.

Só no Brasil são 13.950.448 milhões de motocicletas, equivale a 21,5\% do total de veículos. No Ceará a frota de motocicletas já é superior a de automóveis (DENATRAN, 2010). De 2004 a 2010, o crescimento na frota de motocicletas no estado do Ceará foi de 128,4\%, passando de 282.826 para 645.998 (DETRAN-CE, 2010).

No município de Quixadá não é diferente, com uma população de 80.605 mil habitantes segundo (SILVA et al, 2011) e a frota de veículos sendo de 17.183 mil, totalizando assim, um veículo para cada 4.69 habitantes. As motocicletas lideram em quantidades, onde são 9.073 $(52,8 \%)$ no total (DETRAN-CE, 2010).

O coeficiente de mortalidade dessa categoria tem-se elevado drasticamente a partir de meados da década de 1990; crescendo 875\% entre 1996 (0,4/100 mil habitantes) e 2006 (3,9/ 100 mil habitantes) (SILVA et al, 2011).

No Brasil, em 1997, entre 40 mil acidentes com veículos de duas rodas, aconteceram 24 mil mortes, e os dados de internação por grupos de causas identificam que, em 1998, foram internados 15.232 motociclistas, vítimas de acidentes de transporte, sendo que, em 2004, este número evoluiu para 27.388, ocorrendo, portanto, um aumento de 79,8\% (SANTOS et al, 2008).

Com o crescimento desordenado dos índices de acidentes de motocicletas em todo o país; torna-se necessária a criação de medidas revolucionárias que sejam capazes de reverter este mal.

O Brasil tem desenvolvido iniciativas importantes em relação ao tema, como foi o CTB, em 1998, um dos fatores responsáveis pela redução nas taxas de mortalidade por acidentes de transporte no país. O CTB é de responsabilidade do Ministério das Cidades (SOUZA et al, 2007). 
De todas as políticas já existentes, a fim de minimizar os altos índices desses agravos, podemos citar o uso do álcool como sendo, ultimamente, prioritário no país pelo fator binominal existente entre condutor e uso do álcool.

Nesse contexto, sabe-se que uma parcela importante dos acidentes de trânsito pode ser atribuída ao consumo excessivo de álcool. Estima-se que 70\% dos casos fatais desses acidentes estão relacionados como uso e abuso de bebidas alcoólicas (JOMAR et al, 2011).

Essas evidências influenciaram o Congresso Brasileiro a implantar, em 2008, a Lei n $^{\circ}$ 11.705 que reduz para zero o nível de alcoolemia permitido, aumenta a penalidade administrativa e criminaliza o condutor que dirigir com $0,6 \mathrm{dcg}$ ou mais de álcool por litro de sangue (MOURA et al, 2009).

Assim como a redução do uso do álcool outras prioridades da política pública têm mostrado avanços significativos, como é o caso da educação. Hoje o tema tornou-se mais comum na real situação enfrentada pelos usuários dos transportes, assim como, também, aos órgãos responsáveis pela segurança desta população. Essa mesma educação teve por vários anos oculta nos existentes códigos que regem as leis de conduta no trânsito.

O comportamento desejável no trânsito é resultante da boa educação em grupo, que também se refletirá em outros setores da vida, indicando que o respeito mútuo e a aceitação das limitações alheias promoverão a segurança e a harmonia na interação entre as pessoas (DETRAN-PR, 2006).

Toda essa problemática deve, além de tudo, contar com a existência de um projeto político que vise uma diminuição considerável em todo o contexto das políticas voltadas à resolução desses agravos causados pelos acidentes e que não sejam só "assistencialistas" e sim preventivos, assim, como resolutivos e contínuos.

É com esta ideia que objetivamos estudar a prevalência dos acidentes de motocicletas envolvendo os adolescentes no período de 2008 a 2010, através dos dados obtidos no órgão competente (DMT de Quixadá), para abordarmos a população em um ponto estratégico do centro da cidade, através de blitz educativa, e explicar a real importância de reverterem esse quadro. 


\section{Material e Métodos}

Trata-se de um estudo retrospectivo e transversal, envolvendo 100 motociclistas adolescentes da cidade de Quixadá/Ceará no período de agosto de 2012 na cidade de Quixadá, cuja amostra foi calculada com base na estimativa da média populacional, tendo um erro amostral de 5\%, grau de confiança de $95 \%$ e percentual mínimo de $7 \%$ utilizando os dados da frota total de motocicletas do município.

Para avaliação epidemiológica foram utilizados os dados dos acidentes de motocicletas do DEMUTRAN de Quixadá no período de 2008 a 2010. Já na avaliação transversal foram utilizados os dados obtidos através de questionários aplicados no momento da Blitz educativa.

Para a pesquisa primária foram incluídos todos os adolescentes entre 10 a 20 anos de idade, segundo classificação do MS (Portaria 980 de 21/12/1989) e a Sociedade Brasileira de Pediatria (1998), que utilizam da motocicleta como meio de transporte. Foram incluídos no estudo transversal, somente adolescentes e que estejam conduzindo a motocicleta no momento da Blitz.

Os dados foram coletados em dois momentos distintos: O primeiro momento implicou num levantamento sobre o perfil sócio demográfico dos acidentes de motocicleta envolvendo os adolescentes fornecidos pelo DEMUTRAN da cidade de Quixadá no período de 2008 a 2010. Os dados obtidos foram utilizados na educação dos motociclistas abordados e para determinar os pontos estratégicos para as Blitz.

Num segundo momento foram realizadas algumas blitz educativas juntamente com os profissionais do DEMUTRAN de Quixadá. Durante a abordagem, foi disponibilizado, para cada participante voluntário, um termo de consentimento livre e esclarecido, onde o motociclista foi esclarecido sobre a pesquisa e assinou (no caso do adolescente ser menor de idade um responsável de maior teve que assinar outro termo - consentindo todas as informações contidas no mesmo, garantindo a preservação de sua identidade, assim como o abandono à pesquisa quando for solicitado.

Foram utilizados como instrumentos de coleta de dados dois questionários pré estruturados: onde o primeiro constou de perguntas sobre o perfil demográfico dos participantes como: idade, sexo, estado civil, renda familiar. $\mathrm{O}$ segundo constou de perguntas relativas ao uso da motocicleta como: habilitação, uso do capacete, uso de bebidas alcoólicas, revisão da 
motocicleta, conhecimento do código de trânsito, histórico de envolvimento em acidentes e participação em blitz educativa.

Foram utilizadas, para análise dos dados, as variáveis adquiridas através das informações fornecidas pelo DEMUTRAN de Quixadá juntamente dos dois questionários objetivos. Em seguida foram tabulados em forma de tabelas e analisados utilizando medidas de tendência central e de dispersão.

Foi entregue o termo de consentimento livre e esclarecido que assegurou o sigilo da identidade e das informações coletadas de cada participante, assim como o livre abandono em qualquer fase da pesquisa sem que haja nenhum dano ao voluntário.

O referido trabalho foi aprovado no comitê de ética em pesquisa com seres vivos da Universidade Estadual do Ceará de Fortaleza, para avaliação ética conforme determina a resolução 196/96, do Conselho Nacional de Saúde.

\section{Resultados}

Quanto aos dados obtidos no DEMUTRAN de Quixadá, no período de janeiro de 2008 a julho de 2010, foram notificados 1.342 acidentes de motocicletas, sendo este o principal transporte responsável pelos eventos, dos quais a maioria aconteceu nos 5 das 74 localidades (bairros e distritos) estudadas, sendo os locais escolhidas para as blitz de acordo com a frequência dos acidentes: No centro foram organizadas duas blitz e nos demais bairros foram feitas apenas uma blitz em cada, totalizando 06 blitz no período de abril a maio de 2012, sendo todos nos finais de semana.

Podemos observar que os resultados expostos na tabela 1 mostram as características sócio-demográficas dos motociclistas adolescentes de Quixadá. 
Tabela 01 - Distribuição da amostra quanto à frequência e a porcentagem dos dados socioeconômicos dos motociclistas abordados. Quixadá-CE. N = 100 .

\begin{tabular}{lcc}
\hline VARIÁVEIS & $\begin{array}{c}\text { Frequência } \\
(f)\end{array}$ & $\begin{array}{c}\text { Porcentagem } \\
(\%)\end{array}$ \\
\hline
\end{tabular}

\section{FAIXA ETÁRIA}

De 10 a 13 anos

$05 \quad 5,0$

De 14 a 17 anos

$52 \quad 52,0$

De 18 a 20 anos

4343,0

\section{SEXO}

Masculino

92

92,0

Feminino

08

8,0

\section{ESCOLARIDADE}

Analfabeto

Ensino fundamental

0

0,0

Ensino médio

Ensino superior

\section{ESTADO CIVIL}

Solteiro

Casado

Divorciado

Outros

\section{TIPO DE TRASNPORTE}

Automóvel

Motocicleta

Outros

Não se aplica

0

\section{PROFISSÃO}

Mototaxi

09

61

Outros

TOTAL

Fonte: autores da pesquisa, 2010

Dos motociclistas entrevistados, 52\% encontravam-se na faixa etária entre 14 a 17 anos, predominando o sexo masculino (92\%), 86\% cursavam o ensino médio, $71 \%$ eram solteiros, $61 \%$ disseram utilizar da motocicleta para trabalhar e $43 \%$ afirmaram exercer a profissão de mototaxi. 
Tabela 02 - Distribuição dos adolescentes quanto às respostas aos questionários relacionados ao uso da motocicleta. Quixadá/CE, 2012. № 100.

\begin{tabular}{|c|c|c|c|c|}
\hline \multirow{2}{*}{$\begin{array}{l}\text { Questionário relacionado ao } \\
\text { uso da motocicleta }\end{array}$} & \multicolumn{2}{|c|}{ SIM } & \multicolumn{2}{|c|}{ NÃO } \\
\hline & $\begin{array}{l}\text { Frequência } \\
\text { (f) }\end{array}$ & $\begin{array}{c}\text { Porcentagem } \\
(\%)\end{array}$ & $\begin{array}{l}\text { Frequência } \\
\text { (f) }\end{array}$ & $\begin{array}{c}\text { Porcentagem } \\
(\%)\end{array}$ \\
\hline Habilitados (Tipo A) & 27 & 27,0 & 73 & $\mathbf{7 3 , 0}$ \\
\hline Conhecimento do CTB & 02 & 2,0 & 98 & 98,0 \\
\hline $\begin{array}{l}\text { Capacete presente na } \\
\text { abordagem }\end{array}$ & 13 & 13,0 & 87 & 87,0 \\
\hline Prática de direção defensiva & 35 & 35,0 & 65 & 65,0 \\
\hline Revisão da motocicleta & 91 & 91,0 & 09 & 9,0 \\
\hline Envolvimento em acidentes & 60 & 60,0 & 40 & 40,0 \\
\hline Conhecimento da "Lei Seca" & 02 & 2,0 & 98 & 98,0 \\
\hline Uso de bebidas alcoólicas & 44 & 44,0 & 56 & 56,0 \\
\hline $\begin{array}{l}\text { Andar com motociclista } \\
\text { alcoolizado }\end{array}$ & 72 & 72,0 & 28 & 28,0 \\
\hline $\begin{array}{l}\text { Participação em programas } \\
\text { educativos }\end{array}$ & 03 & 3,0 & 97 & 97,0 \\
\hline Existe programa educativo & 10 & 10,0 & 90 & 90,0 \\
\hline $\begin{array}{l}\text { Já foi abordado em Blitz sobre } \\
\text { educação no trânsito }\end{array}$ & 07 & 07,0 & 93 & 93,0 \\
\hline
\end{tabular}

Fonte: autores da pesquisa, 2010

A tabela 2 nos mostra que, dos motociclistas abordados na pesquisa, $72 \%$ não eram habilitados, sendo que 98\% afirmaram não conhecer o Código de Trânsito Brasileiro, dos quais $87 \%$ não portavam do capacete no momento da abordagem, $65 \%$ não praticavam a direção defensiva, $91 \%$ verbalizaram fazer as revisões das motocicletas em períodos estabelecidos pelo 
fabricante, $60 \%$ disseram já ter se envolvido em acidentes, em relação ao conhecimento da lei 11.705 de 19 de junho de 2008 ("Lei Seca") 98\% afirmam desconhecer, 44\% disseram ter usado bebida alcoólica ao pilotar a motocicleta, $72 \%$ já andaram com motociclistas alcoolizados, 97\% expressaram nunca ter participado de programas educativos, apenas $03 \%$ da ocorrência de programas educativos foram nas escolas, $90 \%$ declararam a inexistência de educação no trânsito e 93\% proferiram nunca terem sido abordados em Blitz educativa.

\section{Discussão}

A pesquisa permitiu o conhecimento de dados relevantes sobre esta população tão prevalente em acidentes de motocicleta.

$\mathrm{Na}$ análise, predominam o gênero masculino como principal usuário de motocicletas, dos quais na faixa etária entre 14 a 17 anos, indicando a menor idade e, portanto, não deveriam estar na responsabilidade de pilotar um transporte tão prevalente em dados de morbimortalidade decorrentes do mau uso do mesmo.

A habilitação do jovem condutor de veículos automotores representa verdadeiro rito de passagem no mundo moderno. Cabendo assim aos responsáveis o incentivo a prática da legalidade, limitando-os ao uso dos veículos a partir dos 18 anos como estabelece a lei (ANJOS et al, 2007). Já a predominância do sexo masculino se deve, provavelmente, à maior exposição dos homens no trânsito, influenciada social e culturalmente para que assumam maiores riscos ao conduzir veículos (CAIXETA et al, 2010).

O grau de escolaridade encontrado assemelha-se ao de outros estudos, em que a maioria não ultrapassava o nível médio (PINTO; WITT, 2008). Deste modo, podemos inserir estratégias preventivas em relação ao grupo de maior vulnerabilidade, não esquecendo os demais grupos. Pois é necessário haver intervenções educativas nos níveis de Ensino Fundamental, Médio e Superior (SANTOS et al, 2008).

O adolescente, principalmente solteiro, necessita trabalhar visando a sua independência financeira ou até mesmo para assumir a responsabilidade nas despesas diárias de sua família. Sendo assim a motocicleta tornou-se indispensável tanto pela facilidade de adquirir (baixo custo) quanto pela garantia de serviços autônomos, como é o caso do crescente número de mototaxistas. Essa profissão exige muito do trabalhador, requerendo agilidade e precisão que 
muitas vezes são comparadas com urgência e a competição (CAIXETA et al, 2010). Portanto os profissionais, que utilizam da motocicleta para trabalhar, necessitam ser inseridos em um grupo preferencial de eventos que eduquem, capacitem e regularizem seu trabalho, assegurando seus direitos.

A tabela 2 indica os dados referentes ao uso da motocicleta. No caso do adolescente ser ou não habilitado, a pesquisa mostrou que a maioria estava trafegando irregularmente e que a alta frequência de condutores menores de 18 anos de idade e de jovens não habilitados é extremamente preocupante (FRANÇOSO; COATES, 2008).

Quanto ao Código Brasileiro de Trânsito foi verificado que a população desconhece os seus direitos e deveres enquanto pedestres e usuários do sistema de trânsito (CAMPOS; BARRAL; SANTOS; ZUMIOTTI, 2007); pois a maioria referiu "nunca ter lido ou visto este código".

Referente ao capacete grande parte não utilizava o equipamento. Sabemos que a Resolução no .203 do Conselho de Trânsito Brasileiro, em seu art. $1^{\circ}$, diz ser obrigatório, para circular nas vias públicas, o uso de capacete pelo condutor e passageiro de motocicleta, e que o uso desse equipamento pode reduzir o número e a severidade dos ferimentos na cabeça e pescoço, além de evitar os traumatismos cranioencefálicos e as fraturas cervicais (SANTOS et al, 2008).

Em relação à prática de direção defensiva, observamos a imprudência do condutor. Esses dados tornam-se previsíveis pelo “comportamento natural” desta faixa etária, sendo estes somados à inexperiência na condução de veículos, o desconhecimento das normas de trânsito, a facilidade no uso do álcool, a sensação de invulnerabilidade causando a impressão de imortalidade, fruto da falta de consciência de risco (ANJOS et al, 2007). No caso do trabalhador, a busca de aumento da produtividade adotando medidas inseguras, tais como manobras arriscadas e alta velocidade, podem explicar a alta ocorrência de acidentes ocupacionais com motocicletas (CAIXETA et al, 2010).

A revisão da motocicleta previne o condutor de diversos eventos decorrente do mau uso ou má conservação da mesma. A causa dos acidentes é multifatorial e está relacionado com uma combinação de fatores salientando, dentre os vários, as condições de conservação das motocicletas estando entre as principais (VIEIRA et al, 2011).

Em relação ao envolvimento dos motociclistas em acidentes; o que se explica é o fato da maioria serem trabalhadores e usuários constantes das motocicletas como é o caso dos 
mototáxis e motoboys, sendo incentivados a competição pelos patrões e clientes (VERONESE; OLIVEIRA, 2006). Portanto, a busca de aumento da produtividade adotando medidas inseguras, tais como manobras arriscadas e alta velocidade podem explicar a alta ocorrência de acidentes ocupacionais com motocicletas (CAIXETA et al, 2010).

Outro fato pode ser observado quanto à experiência, pois um motociclista inexperiente contribui para o risco do acidente de trânsito [...]. Já o excesso de experiência pode levá-lo a aprender modos arriscados de dirigir (VERONESE; OLIVEIRA, 2006).

Quanto ao conhecimento por completo da lei 11.705 de 19 de junho de 2008 ("Lei seca"), a maioria afirmou não conhecer, mostrando a necessidade de inserção do tema no diaa-dia da população através de estratégias educativas para só então haver fiscalização.

Quanto à utilização de bebidas alcoólicas ao conduzir a motocicleta, observamos que a maioria confirmou o uso mesmo sabendo que há uma maior probabilidade de ocorrer futuros acidentes. Pois a ingestão de álcool retarda os reflexos e afeta a visão, além de causar sensação de euforia que induz o motorista a abusar da velocidade com perda do controle da motocicleta (VIEIRA et al, 2011).

Entre os entrevistados, grande parte afirmou já ter andado com motoqueiro alcoolizado; mesmo havendo forte relação entre a ingestão de álcool e acidentes de trânsitos. Tratando-se de um hábito lamentável, responsável pela perda de muitas vidas, visto que o condutor alcoolizado apresenta quatro vezes mais possibilidades de não fazer o uso do capacete (SANTOS et al, 2008).

Quanto à participação em programas educativos grande parte referiu não existir. Portanto a busca do envolvimento escolar no desenvolvimento de políticas públicas parece ser um caminho natural para prevenção e redução dos acidentes de trânsito a médio e longo prazo, por meio do acompanhamento dos pais e da formação de pedestres e motoristas mais conscientes (CAIXETA et al, 2010).

Quanto à participação em programa educativo, pequena parte (3\%) ocorreu na escola. Mesmo com este dado negativo sabemos que a escola pode oferecer boa oportunidade de intervenção, tendo em vista a importância da educação na prevenção dos acidentes de transporte e que o próprio Código de Trânsito Brasileiro preconiza que a união, estados, municípios e o Distrito Federal devem interagir para promover a educação para o trânsito, da pré-escola ao terceiro grau (CAIXETA et al, 2010). 
Em relação à existência de educação no trânsito de Quixadá, grande parte afirmou não haver. Deve-se saber que a educação em saúde não se restringe apenas à prevenção de doenças e agravos, constitui um processo de qualificação do indivíduo [...]. As formas de prevenção de agravos à saúde são efetivas por intermédio de uma ação interdisciplinar e intersetorial (transporte, engenharia de tráfego, segurança, educação e saúde) (VIEIRA et al, 2011).

Quanto à abordagem educativa no trânsito a maioria dos usuários afirmou inexistir, prevalecendo o ato da punição através de multas. Sabemos que medidas educativas são importantes e bastante utilizadas, porém não são efetivas, principalmente quando utilizadas isoladamente (BACCHIERI; BARROS, 2011), e que campanhas específicas de prevenção deveriam ser expostas e leis rigidamente aplicadas (JOMAR et al, 2011).

\section{Conclusão}

O presente estudo pôde identificar o perfil demográfico dos motociclistas, assim como possíveis fatores relacionados aos acidentes envolvendo essa população.

Com isso concluí que este tema deve ser explorado e aprofundado por outros pesquisadores, para que haja a formação de novos projetos e posteriormente chegarmos a um melhor diagnóstico da situação vivenciada por esta população quanto ao trânsito e consequentemente intervir nos fatores mais relacionados aos acidentes, a fim de se ter um melhor resultado na redução desses agravos.

Um trabalho educativo e preventivo voltado aos condutores de motocicletas deve ser realizado em datas e locais pré-estabelecidas, garantindo a permanência e a continuidade dos mesmos.

A capacitação dos profissionais envolvidos e a formação dos motociclistas é algo que deve ser aplicado. Pois aos profissionais, além de todo conteúdo obrigatório, deve se educar para saber educar; é saber acima de tudo ser um educador de trânsito e não só atuar no trânsito, frequentando locais estratégicos e buscando a melhoria na relação binomial Condutor/Agente de Trânsito. Ao condutor caberá a observação, aprendizado e aplicabilidade em sua prática diária de tudo o que foi passado pelo agente de trânsito. 


\section{Referências}

ANDRADE, L.M. et al. Acidentes de motocicleta: características das vítimas e dos acidentes em hospital de Fortaleza - CE, Brasil. Rev. Rene. Fortaleza, v. 10, n. 4, p. 52-59, out. 2009. Disponível em: http://www.revistarene.ufc.br/vol10n4_html_site/a06v10n4.htm.

ANJOS, K.C. et al. Paciente vítima de violência no trânsito: análise do perfil socioeconômico, características do acidente e intervenção do Serviço Social na emergência. Acta ortop. bras., São Paulo, v. 15, n. 5, 2007.Available from <http://www.scielo.br/scielo.php?script=sci_arttext\&pid $=$ S1413-78522007000500006\&lng $=$ en\&nrm=iso $>$.

BACCHIERI, G.; BARROS, A.J.D. Traffic accidents in Brazil from 1998 to 2010: many changes and few effects. Rev. Saúde Pública, São Paulo, v. 45, n. 5, Oct. 2011. Available from $<\mathrm{http} / / / \mathrm{www}$. scielo.br/scielo.php?script=sci_ arttext\&pid=S0034-89102011000500017 \&lng= en\&nrm=iso $>$.

CAIXETA, C.R. et al. Morbidade por acidentes de transporte entre jovens de Goiânia, Goiás. Ciênc. Saúde Coletiva [online]. 2010, vol.15, n.4, pp. 2075-2084. Disponível em: $<\mathrm{http} / / / \mathrm{www}$. scielo.br/scielo.php?script=sci_arttext\&pid $\quad=$ S1413-81232010000400021\&lng= en\&nrm=iso $>$.

CAMPOS, A.K.; BARRAL, E.M.R.; SANTOS, S.J.; ZUMIOTTI, V.A. Paciente vítima de violência no trânsito: análise do perfil socioeconômico, características do acidente e intervenção do serviço social na emergência. Acta Ortopédica Brasileira, 2007; 15262-266. Disponible en:http://redalyc.uaemex.mx/redalyc/src/inicio/ArtPdfRed.jsp?iCve $=65715506$.

DENATRAN 2010: Frota de veículos cresce 119\% em dez anos no Brasil, aponta Denatran. Disponível em: http://www.denatran.gov.br/ultimas/frota.htm. Acesso em: 27 de Jan. 2011.

Detran/CE - Departamento de Trânsito do Ceará. Trânsito Seguro. Fortaleza-CE, 2010. Disponível em: http://www.detran.ce.gov.br/consultas /arquivos/cartilhas/DIRECAO_DEFENSIVA.pdf.

Detran/PR - Departamento de Trânsito do Paraná. Comunidade e Trânsito. Educar para o Trânsito. TECNODATA; Curitiba-PR, 2006. 20 $0^{\mathrm{a}}$ Ed. 30p. Disponível em: $<$ http://www.educacaotransito.pr.gov.br/arquivos/File/Comunidade/Educar\%20para\%20o\%20Transito .pdf $>$.

FRANÇOSO, L.A.; COATES, V. Repercussões sociais das sequelas físicas em adolescentes vítimas de acidentes de trânsito. Adolesc. Saude. 2008; 5(1): 6-13. Disponível em: < http://www.adolescenciaesaude.com/detalhe_artigo.asp?id=64\#>.

JOMAR, R.T. et al. Educação em saúde no trânsito para adolescentes estudantes do ensino médio. Esc. Anna Nery [online]. 2011, vol.15, n.1, pp. 186-189. Disponível em <http://www.scielo.br/scielo.php? script=sci_arttext \&pid=S1414-81452011000100026\&lng= pt\&nrm=iso $>$.

LABIAK, B. et al. Fatores de exposição, experiência no trânsito e envolvimentos anteriores em acidentes de trânsito entre estudantes universitários de cursos na área da saúde, Ponta Grossa, PR, Brasil. Saúde Soc., [online]. 2008, vol.17, n.1, pp. 33-43. Disponível em: <http://www.scielo.br/scielo.php?script=sci_arttext\&pid=S0104-12902008000100004\&lng= en\&nrm=iso $>$. 
MOURA, E.C. et al. Direção de veículos motorizados após consumo abusivo de bebidas alcoólicas, Brasil, 2006 a 2009. Rev. Saúde Pública, [online]. 2009, vol.43, n.5, pp. 891-894. Disponível em: http://www.scielo.br /scielo.php?script=sci_arttext\&pid=S0034891020090 00500021\&lng=en\&nrm= iso.

PAULINO, L.C. Trânsito no Brasil: desafios à efetivação do direito de ir e vir e permanecer vivo. Fortaleza-CE, Ed Imprece/2010, vol. 1, PP. 66-7.

PINTO, A.O.; WITT, R.R. Gravidade de lesões e características de motociclistas atendidos em um hospital de pronto socorro. Revista gaúcha de enfermagem. Porto Alegre. Vol. 29, n.3 (jun. 2008), p. 408-414. Available from: <http://hdl.handle.net/10183/23604>.

SANTOS, A.M.R. et al. Perfil das vítimas de trauma por acidente de moto atendidas em um serviço público de emergência. Cad. Saúde Pública [online]. 2008, vol.24, n.8, pp. 1927-1938. Disponível em: $<$ http://www.scielo.br/ X2008000800021\&lng=pt\&nrm=iso>. scielo.php?script=sci_arttext\&pid=S0102311

SILVA, P.H.N.V. et al . Estudo espacial da mortalidade por acidentes de motocicleta em Pernambuco. Rev. Saúde Pública, São Paulo, v. 45, n. 2, Apr. 2011. Disponível em: $<$ http://www.scielosp.org/scielo.php?script =sci_arttext\&pid=S003489102011000200020\&ln $\mathrm{g}=\mathrm{en} \& \mathrm{nrm}=\mathrm{iso}>$.

SOUZA, M.F.M. et al. Análise descritiva e de tendência de acidentes de transporte terrestre para políticas sociais no Brasil. Epidemiol. Serv. Saúde, Brasília, v. 16, n. 1, PP. 33-44 mar. 2007. Disponível em: http://portal.saude.gov.br/portal/arquivos/pdf/revista_vol16_n1_corrigido.pdf.

VERONESE, A.M.; OLIVEIRA, D.L.L.C. Os riscos dos acidentes de trânsito na perspectiva dos motoboys: subsídios para a promoção da saúde. Cad. Saúde Pública, Rio de Janeiro, v. 22, n. 12, dez. 2006. Disponível em<http://www.scielo.br/scielo.php?script=sci_arttext\&pid=S0102311X2006001200021\& lng=pt\&nrm=iso>.

VIEIRA, R.C.A. et al. Levantamento epidemiológico dos acidentes motociclísticos atendidos em um Centro de Referência ao Trauma de Sergipe. Rev. esc. enferm. USP, São Paulo, v. 45, n.6, Dec.2011. Availablefrom<http://www.scielo.br/scielo.php?script=sci_arttext\&pid=S00806234 $2011000600012 \& \operatorname{lng}=\mathrm{en} \& \mathrm{nrm}=\mathrm{iso}>$.

\section{Como citar este artigo (Formato ABNT):}

BARROS, Francisco Hilângelo Vieira; SILVA; Leonardo Oliveira; ROSENO, Maria Alcione Silva Gomes; OLINDA, Antônia Gomes de; SOUZA, Joaquina Batista Rodrigues de; AMARAL, João Joaquim Freitas do. Prevalência dos Acidentes de Motocicleta Envolvendo os Adolescentes de Quixadá. . Id on Line Rev.Mult. Psic., 2018, vol.12, n.42, Supl. 1, p. 511-524. ISSN: 1981-1179.

Recebido: 08/11/2018;

Aceito: $12 / 11 / 2018$ 